\title{
Dislocation mechanism of deuterium trapping and transport in tungsten under sub-threshold plasma implantation
}

\author{
V.I. Dubinko ${ }^{1 \dagger}$, E.E. Zhurkin ${ }^{2}$, P. Grigorev ${ }^{2}$, D. Terentyev ${ }^{3}$, G. van Oost $^{4}$, A.V. Dubinko \\ S.V. Dmitriev ${ }^{6}$
${ }^{1}$ National Science Center "Kharkov Physical-Technical Institute", Kharkov 61108, Ukraine
${ }^{2}$ Saint-Petersburg State Polytechnic University, St-Petersburg 195251, Russia
${ }^{3}$ SCK $\cdot C E N$, Boeretang 200, $2400 \mathrm{Mol}$, Belgium
${ }^{4}$ Department of Applied Physics, Ghent University, 9000 Ghent, Belgium
${ }^{5}$ Institute of Electrophysics and Radiation Technologies NASU, Kharkov 61002, Ukraine
${ }^{6}$ Institute for Metals Superplasticity Problems RAS, Khalturin St. 39, 450001Ufa, Russia \\ †vdubinko@mail.ru
}

\section{Дислокационный механизм захвата и транспорта дейтерия в вольфраме при подпороговой плазменной имплантации}

\author{
Дубинко В.И. ${ }^{1}$, Журкин Е.Е²., Григорьев Е.Е. ${ }^{2}$, Терентьев Д.А. ${ }^{3}$, Г. ван Ост ${ }^{4}$, \\ Дубинко А.В. ${ }^{5}$, Дмитриев С.В. ${ }^{6}$ \\ ${ }^{1}$ ННЦ “Харьковский физико-технический институт”, Харьков 61108, Украина \\ ${ }^{2}$ Санкт-Петербургский государственный политехнический университет, Санкт-Петербург 195251, Россия \\ ${ }^{3}$ Бельгийский Центр ядерных исследований SCK•CEN, 2400 Мол, Бельгия \\ ${ }^{4}$ Отдел Прикладной Физики, Университет Гента, 9000 Гент, Бельгия \\ ${ }^{5}$ Институт Электрофизики и Радиационных Технологий НАНУ, Харьков 61002, Украина \\ ${ }^{6}$ Институт проблем сверхпластичности металлов РАН, ул. Халтурина 39, 450001 Уфа, Россия
}

\begin{abstract}
Построена модель удержания дейтерия в сплавах вольфрама, основанная на захвате дейтерия дислокациями и диффузии к поверхности по дислокационной сетке с параметрами вычисленными методом ab initio. Модель объясняет наблюдаемые закономерности удержания дейтерия при подпороговой имплантации, не создающей стабильных дефектов, которые обычно рассматриваются как ловушки дейтерия. Насыщение содержания дейтерия с дозой имплантации и эффекты, связанные с легированием вольфрама танталом, описаны в сравнении с экспериментальными данными по плазменной имплантации высокой и низкой интенсивности.
\end{abstract}

Ключевые слова: сплавы вольфрама, удержание дейтерия, дислокации.

\section{Introduction}

The current choice of materials to be used in ITER plasmafacing components includes tungsten and beryllium [1]. The sputtering yield of tungsten is much lower than the one of beryllium, while its melting point is significantly higher. However, the practical use of tungsten is hindered by its high ductile-to-brittle transition temperature and therefore high brittleness at the temperatures of operation. In order to improve the mechanical properties, tungsten alloys are con-
We develop a model for $\mathrm{D}$ retention in $\mathrm{W}$ alloys based on deuterium trapping at dislocations and transport to the surface via the dislocation network with parameters evaluated by ab initio calculations. The model can explain experimentally observed trends of $\mathrm{D}$ retention in $\mathrm{W}$ under sub-threshold implantation, which does not produce stable defects that act as $\mathrm{D}$ traps in conventional models. Saturation of $\mathrm{D}$ retention with implantation dose and effects due to alloying $\mathrm{W}$ with Ta are evaluated and compared with experimental observations under low and high flux plasma implantation conditions.

Keywords: tungsten alloys, deuterium retention, dislocations.

sidered. One of the issues still to be clarified is the retention of hydrogen isotopes (including deuterium and radioactive tritium) in tungsten alloys.

In current models dealing with deuterium (D) retention in tungsten [2], it is argued that nucleation of D-complexes is determined crucially by the concentration of radiationproduced vacancies, which act as traps for fast migrating $\mathrm{D}$ atoms. One vacancy has been argued to trap up to six hydrogen atoms [3, 4]. At sufficiently low temperatures 
considered in ref. [2] vacancies are immobile while SIAs diffuse and become trapped at impurity atoms (mainly carbon, C) or are absorbed by dislocations. So the result strongly depends on the dislocation density and C-SIA trapping energy, which have to be high enough to trap SIA's so that the remaining vacancies could trap D atoms and act as nucleation cites for D-clusters. This model was developed to describe the ion implantation with energy of 5-30 keV, and it cannot be applied (even qualitatively) to the nucleation of D-clusters at sub-threshold implantation conditions, i.e. when the ion energy is too low to produce stable vacancySIA pairs in the crystal bulk. While the sub-threshold implantation conditions are important, since they reflect the plasma-wall interaction expected to occur in the ITER and experiments involving high-flux high temperature deuterium plasmas with ion energies of $\sim 50 \mathrm{eV}[5,6]$. Experimental investigations of trapping and release of $\mathrm{D}$ in pure tungsten (W) and tungsten-tantalum (W-Ta) alloys show that there is a considerable amount of trapped D in the bulk up to several microns depth, where no vacancies can be expected since their thermal concentration at the implantation temperature $(<500 \mathrm{~K})$ is negligible. Hence, the description of the trapping of $\mathrm{D}$ at these irradiation conditions requires alternative mechanisms as compared to those considered in the current models.

\section{Homogeneous self-trapping of deuterium in the bulk}

Ab initio calculations [4] show that two hydrogen atoms trap each other weakly with a binding energy $E_{b} \sim 0.01 \mathrm{eV}$, (as compared e.g. with helium forming strong pairs with a binding energy of $E_{b} \sim 1 \mathrm{eV}$ ).

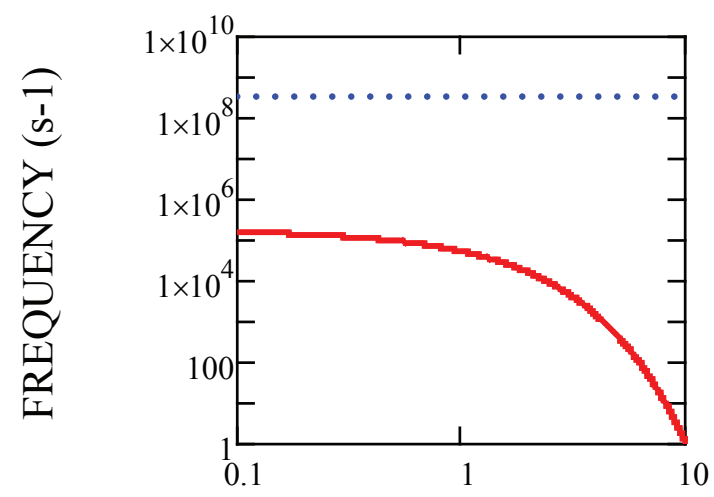

\section{DEPTH (microns)}

\section{- Trapping … Detrapping}

Fig.1. Trapping vs. detrapping frequencies for D-D pairs in the bulk under typical implantation conditions (see Fig. 2).

Fig. 1 shows detrapping frequency, $w_{\text {de }}$, for $\mathrm{D}-\mathrm{D}$ pairs based on these estimates, vs. trapping frequency, $w_{D D}$, i.e. the frequency of collisions of one $\mathrm{D}$ atom with others having a concentration of $C_{D}^{b}$ in the crystal bulk, which are given by the following expressions:

$$
\begin{gathered}
w_{D D}=\alpha_{D D} C_{D}^{b}, \alpha_{D D}=\frac{4 \pi}{\omega}\left(\frac{3 \omega}{4 \pi}\right)^{1 / 3} D_{D}^{b}, \\
D_{D}^{b} \approx b^{2} w_{0} \exp \left(-\frac{E_{m}^{b}}{k_{B} T}\right) \\
w_{\mathrm{de}}=w_{0} \exp \left(-\frac{E_{b}+E_{m}^{b}}{k_{B} T}\right), w_{0}=10^{13} s^{-1},
\end{gathered}
$$

where $\omega \approx 0.5 b^{3}$ is the atomic volume, $\mathrm{b}$ is the atomic spacing, $D_{D}^{b}$ is the bulk diffusion of $\mathrm{D}$ atoms, $w_{0}$ is the frequency factor, $E_{m}^{b}$ is the bulk migration energy and $k_{B} T$ has the usual meaning.

One can see that the trapping frequency decreases with distance (depth) from the surface due to decreasing $C_{D}^{b}$ (see the next section) and it is several orders of magnitude lower than that of detrapping. So a homogeneous nucleation of $\mathrm{D}$ (or $\mathrm{H}$ ) clusters is indeed very questionable in that case, and one needs an alternative trapping mechanism for $\mathrm{D}$ atoms at some intrinsic defects to provide the nucleation cites for gas clusters. In the following section we consider a model of D trapping by dislocations, which does not require vacancies as the nucleation cites.

\section{Trapping of deuterium by dislocations}

Density functional theory (DFT) calculations by the present authors [7] shows that there are at least three positions inside of the screw dislocation core in which $\mathrm{D}$ is trapped with the binding energy $E_{b}^{1}=0.6 \mathrm{eV}$. In addition, there are six positions adjacent to the dislocation core in which $\mathrm{D}$ is trapped with the binding energy of $0.55 \mathrm{eV}$. D atoms can migrate along the dislocation core with an activation energy $E_{m}^{d}=0.1 \mathrm{eV}$ as compared to the bulk migration energy $E_{m}^{b}$ $=0.4 \mathrm{eV}$. A free path of the $\mathrm{D}$ atom along a dislocation before detrapping is given by [8]:

$$
\lambda_{d}^{0}=b \exp \left(\frac{E_{m}^{b}-E_{m}^{d}+E_{b}^{1}}{2 k_{B} T}\right),
$$

and one has $\lambda_{d}^{0}>10$ micron at $\mathrm{T}<460 \mathrm{~K}$, which means that $\mathrm{D}$ atoms practically don't leave the dislocation core while being trapped and so they can form n-D clusters sitting (or migrating) at the dislocation. The rate of trapping of a subsequent atom by a n-D cluster $w_{n}^{+}(x)$ placed at the depth $x$ is given by the product of the $\mathrm{D}$ flux from the bulk to the unite length of the dislocation $J_{d}^{D}$, and the length along the dislocation from which each cluster is fed up with migrating D-atoms, $\lambda_{d}$ :

$$
w_{n}^{+}(x)=J_{d}^{D} \lambda_{d}, J_{d}^{D}=\frac{Z_{d}}{\omega} D_{D}^{b} C_{D}^{b}(x),
$$

where $Z_{d} \sim 1$ is the dislocation capture efficiency for D-atoms migrating from the bulk [9]. $w_{n}^{+}(x)$ depends on the depth $x$ via the bulk D-concentration, $C_{D}^{b}(x)$. At a steadystate (i.e. for times larger than the time of $\mathrm{D}$ bulk diffusion to the depth $x) C_{D}^{b}(x)$ is given by 


$$
C_{D}^{b}(x)=\frac{\omega F_{D} x_{D}}{D_{D}^{b}} \exp \left(-x k_{D}\right), k_{D} \approx\left(Z_{d} \rho_{d}\right)^{0.5}
$$

where $F_{D}$ is the D ion flux, $x_{D}$ is the implantation straggling, and $k_{D}$ is the sink strength for migrating $\mathrm{D}$-atoms. Fig. 2 shows that the depth of $\mathrm{D}$ penetration is determined mainly by the dislocation density, $\rho_{d}$, which act as the main sink for migrating atoms.

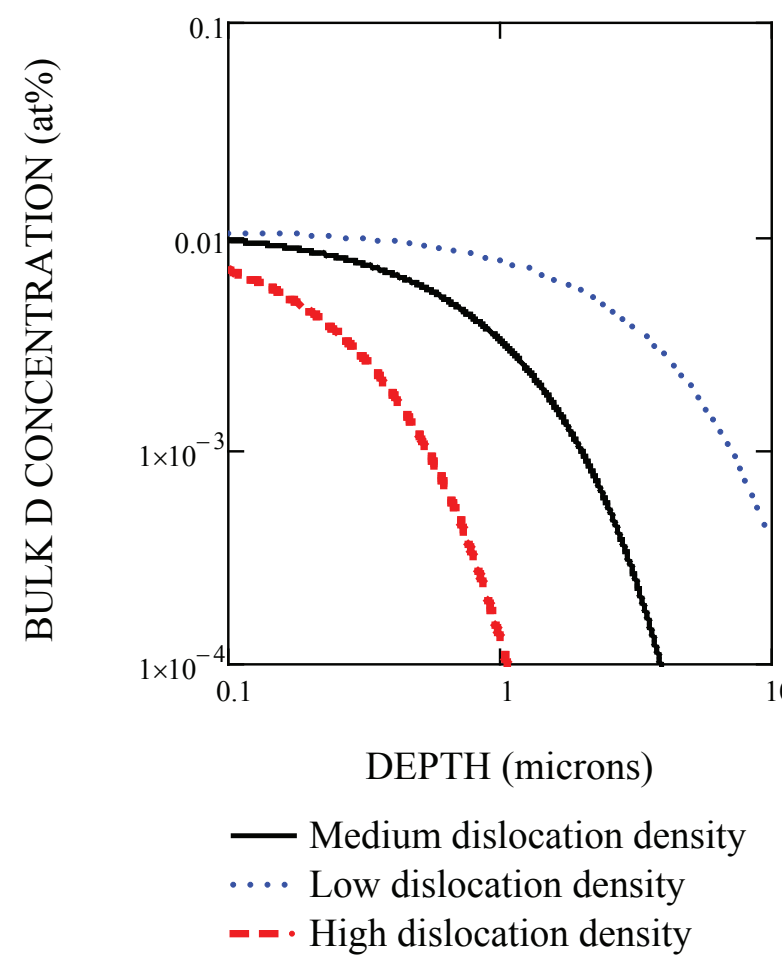

Fig.2. Steady-state D-concentration in the bulk, $C_{D}^{b}(x)$ at different dislocation densities and the following implantation conditions: Low $\rho_{d}=10^{11} \mathrm{~m}^{-2}$, Medium $\rho_{d}=10^{12} \mathrm{~m}^{-2}$, High $\rho_{d}=10^{13} \mathrm{~m}^{-2}$, $F_{D}=10^{20} \mathrm{~m}^{-2} \mathrm{~s}^{-1}, x_{D}=\mathrm{b}, \mathrm{T}=460 \mathrm{~K}$.

Now we can determine a sufficient condition for D clustering at dislocations by comparing the rate of trapping (5) with the rate of detrapping of an atom from n-D cluster, $w_{n}^{-}$ , which is given by

$$
w_{n}^{-}=w_{0} \exp \left(-\frac{E_{b}^{n}+E_{m}^{d}}{k_{B} T}\right),
$$

where $E_{b}^{n}$ is the binding energy between one $\mathrm{D}$ and n-D cluster. DFT calculations [7] give the following values for $n=2 \div 5: E_{b}^{2}=0.55 \mathrm{eV}, E_{b}^{3}=0.6 \mathrm{eV}, E_{b}^{4}=0.48 \mathrm{eV}$, $E_{b}^{5}=0.45 \mathrm{eV}$.

One can see from Fig. 2 that at high dislocation density, D-concentration falls down sharply below a micron depth, whereas at medium and low dislocation densities it extends to several microns so that the trapping rate of a $\mathrm{D}$-atom by $\mathrm{n}-\mathrm{D}$ cluster exceeds its detrapping in this region as shown in Fig. 3, which provides sufficient conditions for the Dclustering at dislocations up to a depth of several microns, which agrees with experimental data on high-flux low-energy plasma implantation $[5,6]$ that detected $\mathrm{D}$ retention in $\mathrm{W}$ and $\mathrm{W}-5 \%$ Ta alloy up to 5 micron depth.

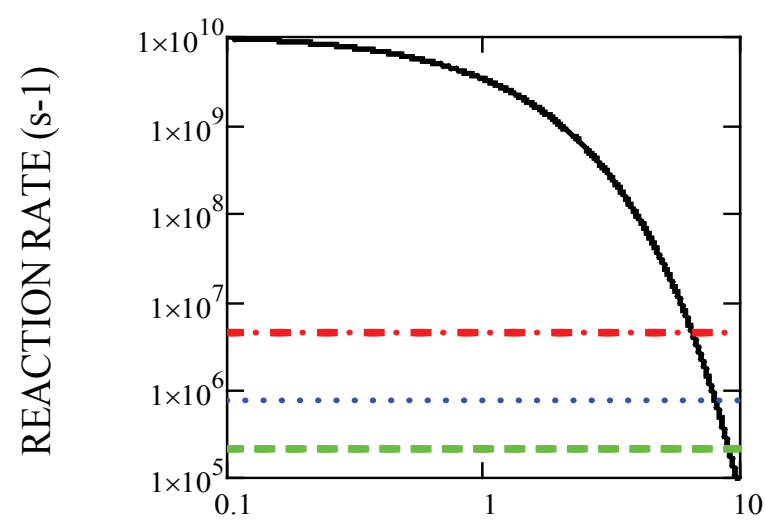

DEPTH (microns)

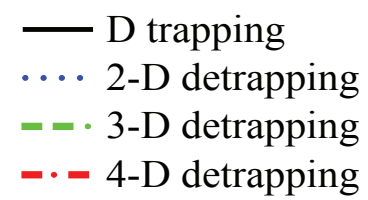

Fig.3. D atom trapping/detrapping reaction rates by/from $n-D$ cluster sitting at a dislocation under implantation conditions shown in Fig.

2, $\rho_{d}=10^{12} \mathrm{~m}^{-2}$ and $\lambda_{d}=\lambda_{d}^{0}<\rho_{d} / N_{C}$ '

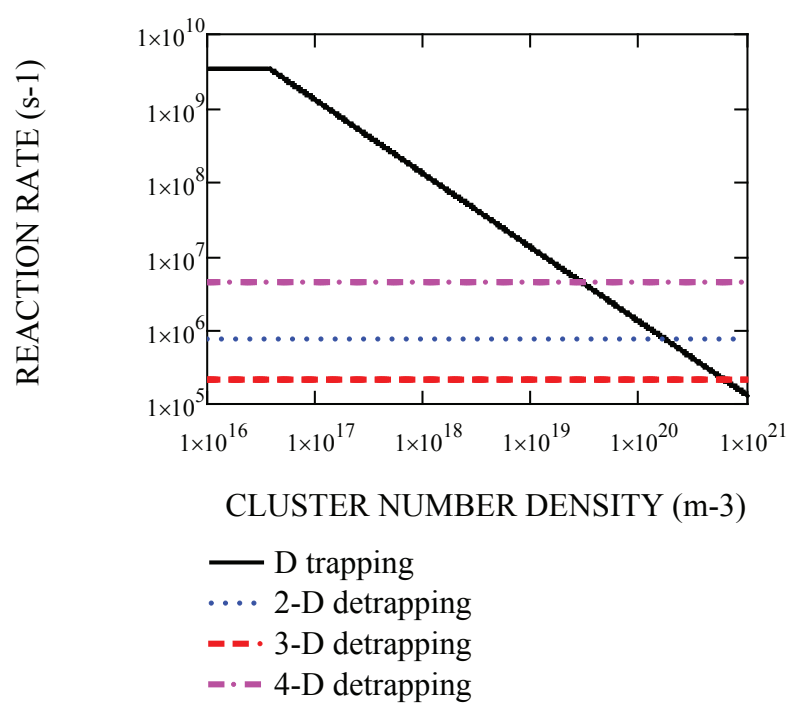

Fig.4. $\mathrm{D}$ atom trapping/detrapping reaction rates by/from n-D cluster sitting at a dislocation vs. cluster number density $N_{\mathrm{c}}$ at $\lambda_{d}=\rho_{d} / N_{c}<\lambda_{d}^{0}$ at the depth of 1 micron.

Naturally, as the clustering process starts, the distance along the dislocation from which each cluster is fed up with migrating D-atoms, $\lambda_{d}$, becomes determined by the cluster number density $N_{c}: \lambda_{d}=\rho_{d} / N_{c}$ as soon as $N_{c}$ becomes larger than $\rho_{d} / \lambda_{d}^{0}$. Accordingly, the trapping rate will decrease inversely proportional to $N_{c}$, as shown in Fig. 4, which will limit the ultimate number density of $\mathrm{D}$ clusters nucleated at dislocations at about $N_{C}^{\max } \approx 10^{19} \div 10^{20} \mathrm{~m}^{-3}$, which would correspond to the mean cluster spacing $\lambda_{\mathrm{d}} \approx 100 \div 10 \mathrm{~nm}$.

Note that $\mathrm{D}$ trapping/detrapping balance from/to the bulk by/from dislocations, which actually determines the deuterium retention in the present model, is not expected to depend strongly on the clustering kinetics. Roughly, the net 
trapping rate of $\mathrm{D}$ at dislocations is given by the following difference:

$$
\left(\frac{d C_{D}^{d}(x)}{d t}\right)_{b}=Z_{d} \rho_{d} D_{D}^{b}\left[C_{D}^{b}(x)-\exp \left(-\frac{E_{b}^{1}}{k_{B} T}\right)\right]
$$

which is positive at depth up to 5 micron depth as can be seen from Fig. 5.

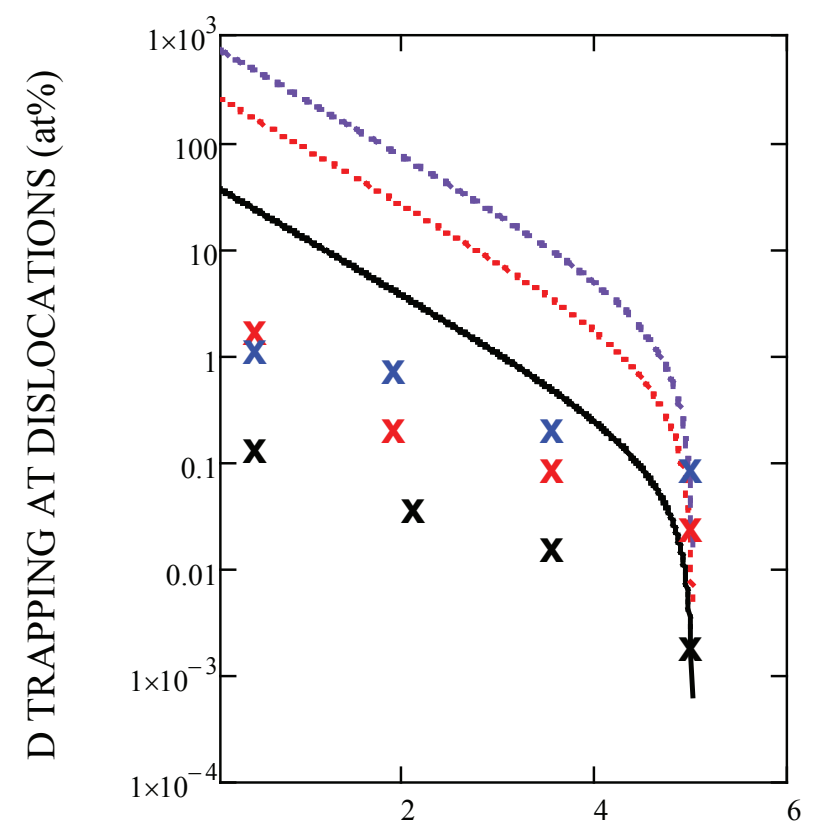

\section{DEPTH (microns)}

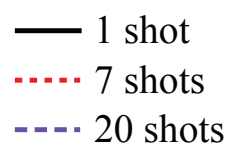

Fig.5. Depth profile of D-trapped at dislocation vs. number of implantation shots $(1$ shot time $=70 \mathrm{~s})$ at implantation conditions shown in Fig. 2, $\rho_{d}=10^{12} \mathrm{~m}^{-2}$ assuming immobile D-clusters. Symbols $\mathbf{x}$ show data $[5,6]$ for the corresponding number of shots.

If all trapped deuterium was retained at dislocations in the form of immobile clusters, then its retention would increase with time as $C_{D}^{d}(x, t)=\left(d C_{D}^{d}(x) / d t\right) t$, and it would have been unrealistically high as shown in Fig. 5 in comparison with experimental data $[5,6]$.

Implantation was performed in a number of shots each having duration of $70 \mathrm{~s}$ at the following conditions: surface temperature 460-510 K, ion energy $50 \mathrm{eV}$, ion flux $\sim 8 \times 10^{23}$ $10^{24} \mathrm{~m}^{-2} \mathrm{~s}^{-1}$ corresponding to the total ion fluence of $5 \times 1025$ $\mathrm{m}^{-2}$ in one shot. The number of shots varied from 1 to 20 resulting in $\mathrm{D}$ retention saturated at levels ranging from 0.01 to $0.1 \%$ at a micron depth and reaching several $\%$ near the surface.

In contrast to these observations, the model of immobile D clusters trapped at dislocations predicts no saturation in $\mathrm{D}$ retention by tungsten, and it will be modified in the next section to account for release of $\mathrm{D}$ to the surface via diffusion along dislocation network.

\section{Trapping and release of deuterium by dislocations}

Let's take into account mobility of small D-clusters along dislocations, which should provide deuterium release to the surface via the dislocation network as illustrated in Fig.6.

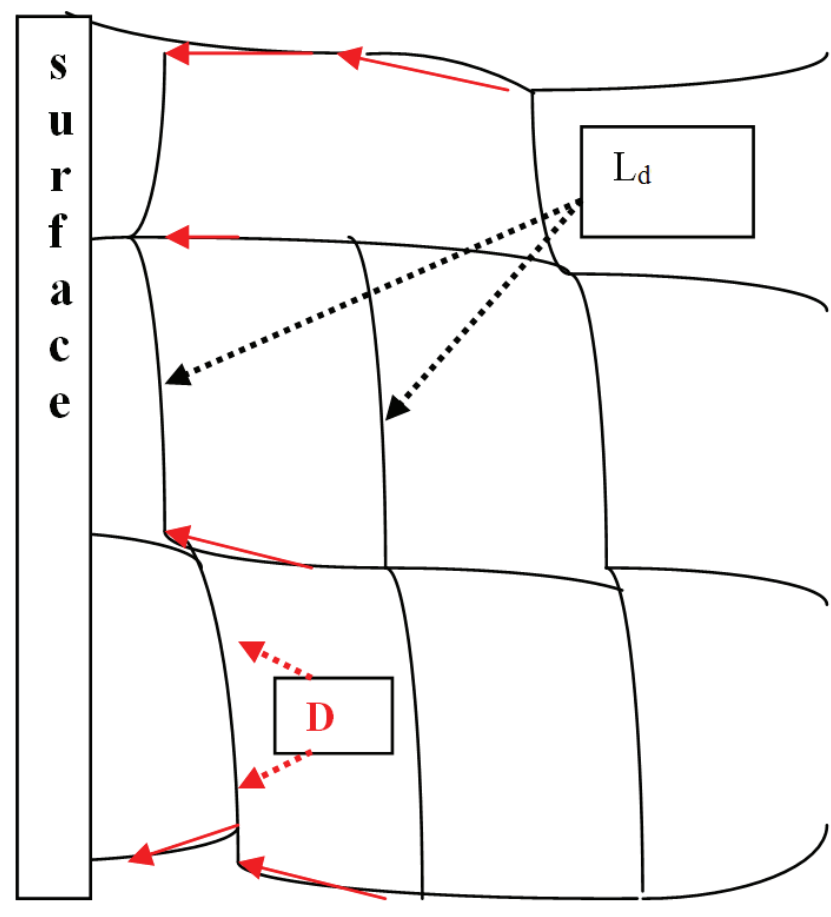

Fig.6. Illustration of D-transport via the dislocation network with dislocation segments $\mathrm{L}_{\mathrm{d}}$.

In this case, the retention rate of deuterium at dislocation would be given by the balance between the net trapping rate of $\mathrm{D}$ by dislocations from the bulk and its transport to the surface via the dislocation network:

$$
\frac{d C_{D}^{d}(x)}{d t}=\left(\frac{d C_{D}^{d}(x)}{d t}\right)_{b}-\sum_{n=1}^{N} \frac{C_{n}^{d}(x)}{\tau_{n}},
$$

where $C_{n}^{d}(x)$ is the concentration of n-D clusters and $\tau_{n}$ is the time it takes for them to reach the surface via the dislocation network, which is given by

$$
\tau_{n}(x)=\frac{x^{2}+L_{d}^{2}}{D_{n}^{d}}
$$

where $D_{n}^{d}$ is the n-D cluster mobility along a dislocation and $L_{d}$ is the mean length of dislocation segments (see Fig.6) that determines diffusion length and time near the surface: $x<<L_{d}$. Substituting (10) into (9) the retention rate takes the following form:

$$
\begin{gathered}
\frac{d C_{D}^{d}(x)}{d t}=\left(\frac{d C_{D}^{d}(x)}{d t}\right)_{b}-\frac{D_{e f f}}{x^{2}+L_{d}^{2}} C_{D}^{d}(x), \\
D_{e f f}=\frac{\sum_{n=1}^{N} D_{n}^{d} C_{n}^{d}}{C_{D}^{d}}, \quad C_{D}^{d}=\sum_{n=1}^{N} C_{n}^{d},
\end{gathered}
$$


where $D_{\text {eff }}$ is the effective diffusivity of deuterium along a dislocation.

In contrast to (8), Eq. (12) has a steady-state solution, which defines the ultimate deuterium retention at the depth $\mathrm{x}$ after transient time, ${ }^{\tau_{s t}}$ :

$$
\begin{gathered}
C_{D}^{d}(x)=\frac{x^{2}+L_{d}^{2}}{D_{e f f}}\left(\frac{d C_{D}^{d}(x)}{d t}\right)_{b}, \\
\tau_{s t}(x)=\frac{x^{2}+L_{d}^{2}}{D_{e f f}}, \quad L_{d}^{2}=\rho_{d}^{-1}
\end{gathered}
$$

Evaluation of $D_{\text {eff }}$ requires DFT calculations, which is beyond the scope of the present paper. We assume here a simple form of $D_{\text {eff }}=b^{2} w_{0} \exp \left(-E_{m}^{e f f} / k_{B} T\right)$ with effective migration energy $E_{m}^{\text {eff }}$, which depends on the dislocation core structure.

The resulting depth profiles of the $\mathrm{D}$ retention at dislocations calculated at different $E_{m}^{\text {eff }}$ values are shown in Fig. 7 vs. experimental data at different numbers of shots. The point of comparison is that $n-D$ clusters may lower their energies by producing jogs on the dislocation. This should hinder D mobility along the core, or effectively, increase $E_{m}^{e f f}$ with increasing implantation time (or the number of shots), which explains the increasing saturation level of $\mathrm{D}$ retention with increasing number of shots.

In conclusion, we address the modification of $\mathrm{W}$ properties by alloying. As argued in ref. [10], alloying components may provide additional binding sites for hydrogen isotopes and may thus increase their retention. This expectation was confirmed by experimental results obtained under low-flux ( 1019 m-2s-1) plasma implantation of D with energy about $1 \mathrm{keV} / \mathrm{D}$ [10]. They seem to be in agreement with the present model, since more binding sites at dislocations should increase $E_{m}^{e f f}$ and thus the D retention.

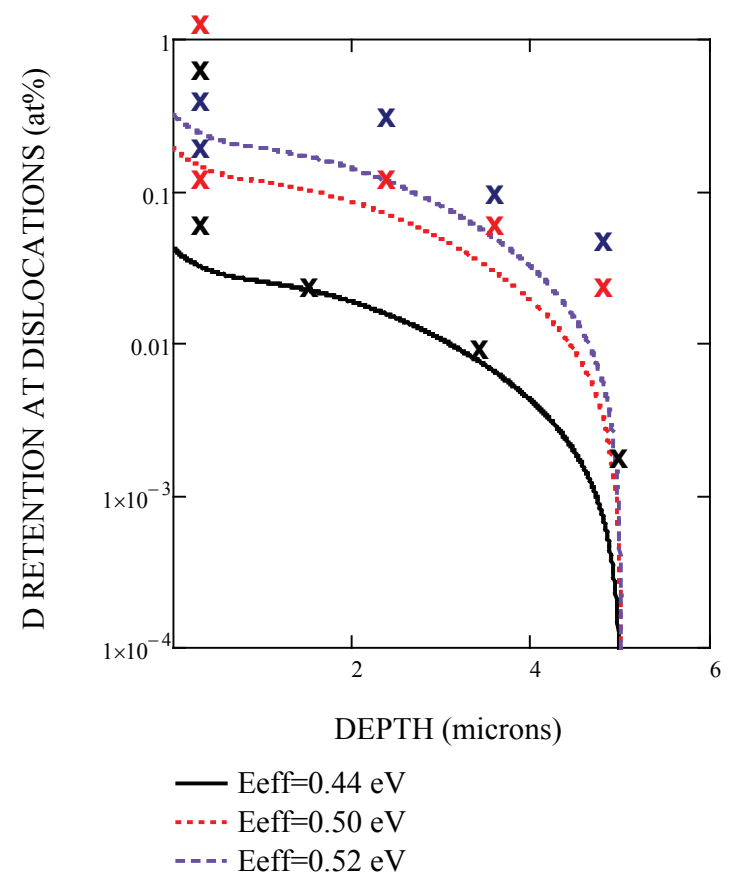

Fig.7. Depth profiles of D retention at dislocations with account of D cluster mobility given by eq. (13) vs. experimental data after different numbers of shots $[4,5]$ shown by symbols X (as in Fig. 5).

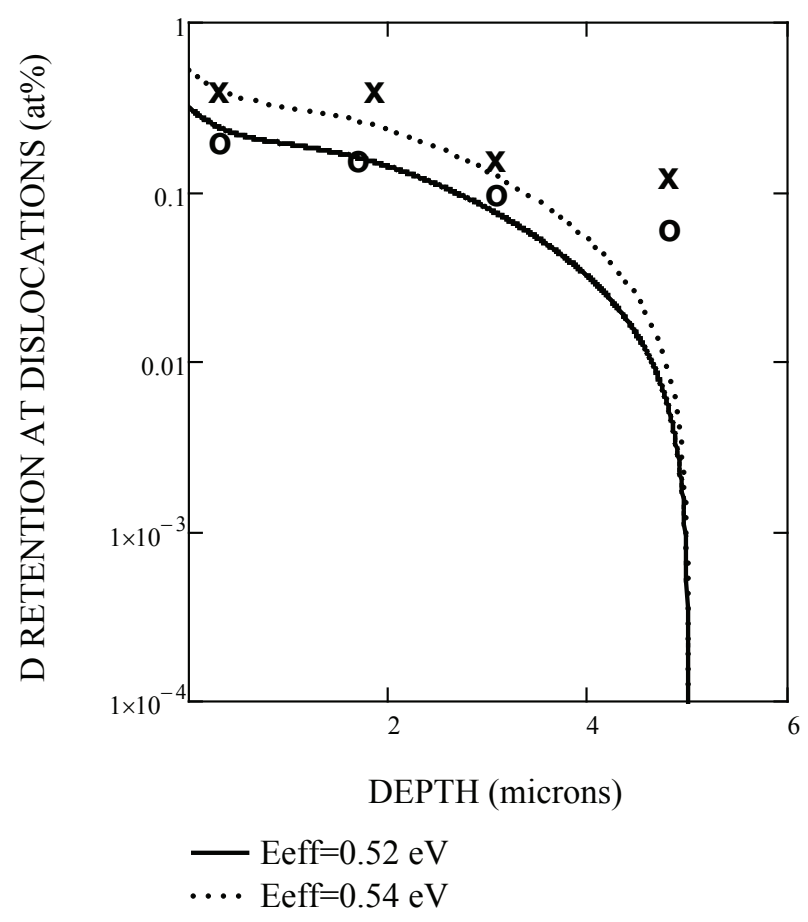

Fig.8. Depth profiles of D retention at dislocations given by eq. (13) vs. experimental data after 20 shots for $\mathrm{W}(\mathrm{x})$ and $\mathrm{W}-5 \% \mathrm{Ta}(\mathrm{o})[4,5]$.

However, the results obtained in $[5,6]$ for high-flux $\left(\sim 10^{24}\right.$ $\mathrm{m}^{-2} \mathrm{~s}^{-1}$ ) plasma implantation show a decreasing $D$ retention in $\mathrm{W}-5 \% \mathrm{Ta}$ as compared to W (Fig. 8). In order to explain this discrepancy between low and high flux implantation results, one needs to take into account the flux dependence of so called "thermally-activated" processes, such as detrapping and migration of $\mathrm{D}$. In the present model, they assumed to be determined only by temperature, which is in line with conventional rate theory of radiation damage [9].

An alternative concept has been proposed in $[9,11-$ 13], according to which these processes are affected by the interaction of structural defects with radiation-induced excitations such as unstable Frenkel pairs, focusing collisions, and mobile discrete breathers (a.k.a. quodons), which are stable quasi-particles that can propagate one-dimensionally and transfer energy along the close packed directions of the lattice. Their interaction with structural defects was shown to modify the rate of migration and detrapping of defects and to make it exponentially dependent on the irradiation flux [13], which may be of crucial importance for the interpretation of the flux effects on $\mathrm{D}$ retention in $\mathrm{W}$ and its alloys. Recently, the existence of discrete breathers in metals has been demonstrated by molecular dynamics with realistic potentials [14]. A detailed analysis of these nonlinear phenomena is beyond the scope of the present paper and will be addressed elsewhere.

\section{References}

1. R. Clark, D. Reiter, Nuclear Fusion Research, Springer, (2005).

2. T. Ahlgren, K. Heinola, K. Vortler, J. Keinonen. 427, 152 (2012).

3. D.F. Johnson, E.A. Carter. J. Mater. Res. 25, 315 (2010).

4. K. O. E. Henriksson, K. Nordlund, A. Krasheninnikov, and

J. Keinonen. Fusion Science and Technology 50, 163113 
(2006).

5. Y. Zayachuk, M.H.J. 't Hoen, P.A. Zeijlmans van Emmichoven, I. Uytdenhouwen and G. van Oost, Nucl. Fusion 52, 103021 (2012).

6. Y. Zayachuk, M. H. J. 't Hoen, P. A. Zeijlmans van Emmichoven, D. Terentyev, I. Uytdenhouwen, G. van Oost. Nuclear Fusion 53, 1 (2013).

7. D. Terentyev, A. Bakaev, V. Dubinko, D. Van Neck and G. Van Oost, Phys. Rev. B, to be published.

8. A.I. Ryazanov, G.A. Arutyunova, V. A. Borodin, Yu.N. Sikursky, V.I. Chuev, J. Nuclear Materials. 110, 62 (1982).

9. V. I. Dubinko, S. Hu, Yu Li, C. H. Henager, Jr. and R.J.
Kurtz. Philosophical Magazine 92 (33), 4113 (2012).

10. K. Schmid, V. Rieger, A. Manhard. J. Nuclear Materials. 426, 247 (2012).

11. V. I. Dubinko, Radiat. Eff. and Defects in Solids. 160, 85 (2005).

12. V.I. Dubinko, V.F. Klepikov, J. Nuclear Materials. 362, 146 (2007).

13. V. I. Dubinko, A. V. Dubinko. Nuclear Inst. and Methods in Physics Research, B 303, 133 (2013).

14. M. Haas, V. Hizhnyakov, A. Shelkan, M. Klopov, A. J. Sievers. Phys. Rev. B 84, 14430 (2011). 